\title{
Congenital Segmental Giant Megaureter Presenting as Cystic Abdominal Mass in a Child
}

\section{Somorendro Paonam* and Sananda Bag}

Max Superspeciality Hospitals, Mohali, Punjab, India

\begin{abstract}
A six years old male child presented with gradually progressive distension of abdomen since one year of his age. Imaging suggested it as a large mesenteric cyst. Further evaluation and intra-operative findings suggested it to be bilateral congenital megaureter with giant one on the left side which was causing gross abdominal distension. Excision of left megaureteric segment, psoas hitch and ureteroneocystostomy was performed. Excision, tapering and uretereroneocystostomy of right ureter was performed. Congenital giant megaureter should be considered as one of differential diagnosis in children presenting as abdominal mass.
\end{abstract}

Keywords: Giant megaureter; Renal descensus; Ureteroneocystostomy; Psoas hitch; Abdominal mass

\section{Introduction}

Megaureter is a generic term indicating the presence of an enlarged ureter with or without concomitant dilatation of the upper collecting system. The normal diameter of ureter is usually $5 \mathrm{~mm}$ in children and rarely exceeds this size. In practice, a ureter with a diameter of $7 \mathrm{~mm}$ or more should be considered as a megaureter [1,2]. Megaureter may be categorized as primary or secondary, refluxing or nonrefluxing, obstructed or non-obstructed, and nonrefluxing nobstructed. In all of these conditions ureteric dilatation is found completely. However, segmental megaureter or segmental cystic dilatation of ureter is a very rare entity and only a few case reports were reported in the literature [3].

\section{Case Report}

A six years old male child presented to us with tense grossly distended abdomen with dilated superficial abdominal veins which had been gradually progressive since infancy. He had no history of dysuria and voiding problems. His hematological and renal function tests including urine routine and urine culture sensitivity were normal. Ultrasound (USG) and Contrast Enhanced Computed Tomography (CECT) scans of abdomen (Figure 1a) showed large cystic abdominal mass suggestive of large mesenteric cyst with bilateral Hydroureteronephrosis (HDUN) secondary to obstruction by the mass. USG guided percutaneous pigtail drainage of cystic mass was done as the child was having respiratory discomfort. Three litres of clear fluid was immediately drained and abdomen got decompressed. Drain fluid creatinine was found to be 40 $\mathrm{mg} / \mathrm{dl}$ which was suggestive of urine. Repeat CECT abdomen (Figure 1b) after a week showed decompressed cystic mass, bilateral HDUN, faint contrast enhancement of left kidney and the tip of the catheter in the enlarged segment of left ureter. Nuclear scan of kidneys showed fifteen percent split function of left kidney. Micturating cystourogram (Figure 2a) showed no reflux and normal voiding pattern with no outflow obstruction. Accidentally in the meantime, the pigtail catheter got dislodged and abdomen got gradually distended again. Intraoperatively, the lower half of left ureter was found hugely dilated with contained urine (Figure $2 b$ ) occupying the whole of abdomen with mildly dilated upper half and a small left kidney. Right ureter was also dilated in the whole course with normal right kidney. Excision of dilated portion of left ureter, left renal descensus, psoas hitch and left ureteroneocystostomy was done. Excision and tapering and right ureteroneocystostomy was also done. He had uneventful recovery period.

On six months follow up after the surgery, the boy is doing well with normal renal function and no recurrence of distension of abdomen. CECT scan shows bilateral enhancing kidneys (Figure 3a) with excretion of contrast in bilateral ureters (Figure 3b).

\section{Discussion}

Megaureter is a spora $\neg$ dic or familial disease, where males are more commonly affected than females and the commonest cause is bladder outlet obstruc $\neg$ tion. In primary obstructive megaureter, the obstruction is at or just above the Uretero-Vesical Junction (UVJ) and is most commonly the result of an adynamic juxtavesical segment of the ureter that fails to effectively propagate urine flow. Bilateral involvement is present in $20 \%$ of the cases with a male-to-female ra $\neg$ tio of 4:1.4 The left side is more commonly affected. On the other hand, secondary obs $\neg$ tructive megaureter results from a functional ureteral obstruction associated with elevated bladder pressures as with

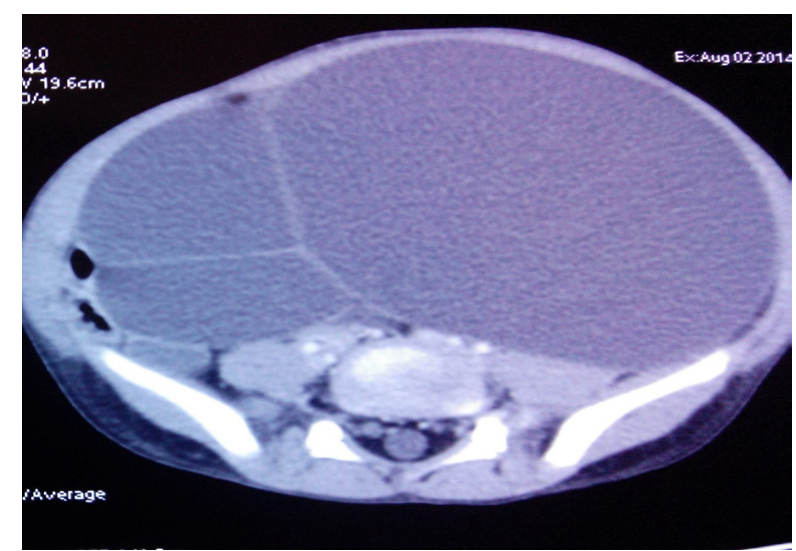

Figure 1a: Large Cystic mass occupying whole of abdomen.

*Corresponding author: Somorendro Paonam, Max Superspeciality Hospitals Mohali, Punjab, India, Tel: 0172665 2000; E-mail: drsomo07@gmail.com

Received September 02, 2015; Accepted October 01, 2015; Published October 08, 2015

Citation: Paonam S, Bag S (2015) Congenital Segmental Giant Megaureter Presenting as Cystic Abdominal Mass in a Child. J Clin Case Rep 5: 614 doi:10.4172/2165-7920.1000614 (2015) Congenital Segmental Giant Megaureter Presenting as Cystic Abdominal Mass in a Child. J Clin Case Rep 5: 614. doi:10.4172/2165-7920.1000614

Copyright: (c) 2015 Paonam S et al. This is an open-access article distributed under the terms of the Creative Commons Attribution License, which permits unrestricted use, distribution, and reproduction in any medium, provided the original author and source are credited. 
Citation: Paonam S, Bag S (2015) Congenital Segmental Giant Megaureter Presenting as Cystic Abdominal Mass in a Child. J Clin Case Rep 5: 614. doi:10.4172/2165-7920.1000614

Page 2 of 3

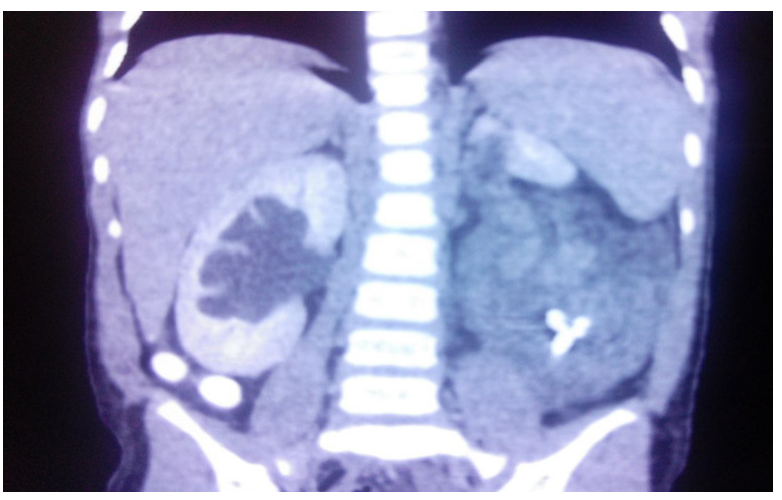

Figure 1b: Decompressed cystic mass after drainage with tip of catheter in dilated left ureter

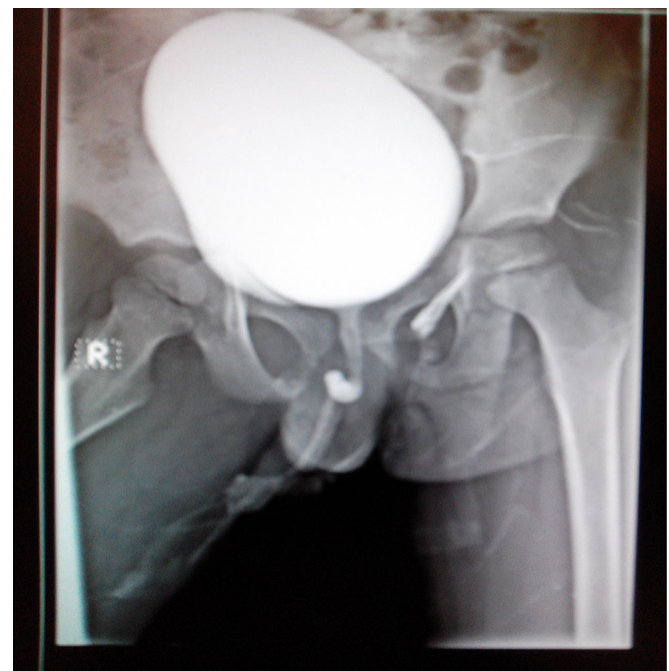

Figure 2a: Normal voiding cystourethrogram.

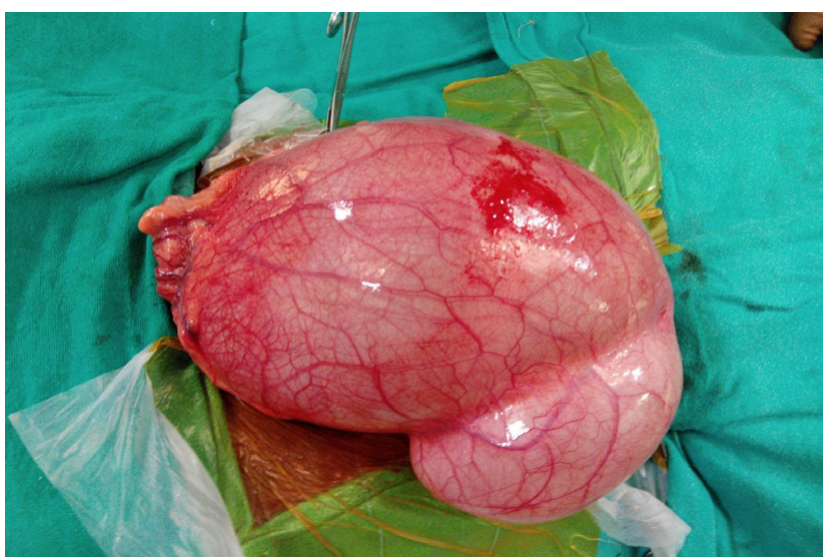

Figure 2b: Intra operative picture showing large dilated lower half of left ureter.

Posterior Urethral Valve (PUV) or Neurogenic Bladder (NGB) that impedes ureteral emptying. Primary refluxing megaureter occurs due to a failure of the anti-reflux mechanism at the UVJ, while secondary refluxing megaureter occurs secondary to PUV and NGB when elevated bladder pressure cau-ses incompetence of the UVJ. Megaureter may be associated with unilateral renal agenesis, complete or incom $\neg$ plete duplex system, ectopic kidney, contrala $\neg$ teral cystic and dysplastic kidney, horseshoe kidney, or Hirschsprung's disease [4]. Imaging studies are useful in the diagnosing the cases of megaureter such as ultrasound, Voiding cysto-urethrogram (VCUG), diuretic nuclear reno $\neg$ graphy, Intravenous Pyelogram (IVP), contrast enhanced CT, and MRI. Important differential diagnoses with megaureters include mesenteric and adnexal masses in females and dilated bo $\neg$ wel loops.

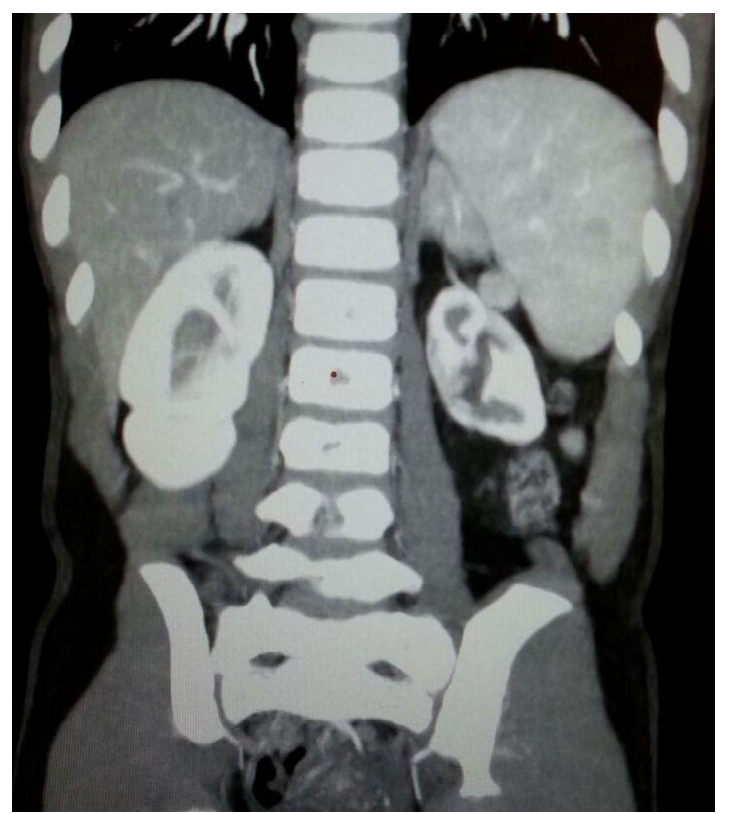

Figure 3a: CECT KUB showing bilateral enhancing kidneys on six months follow up.

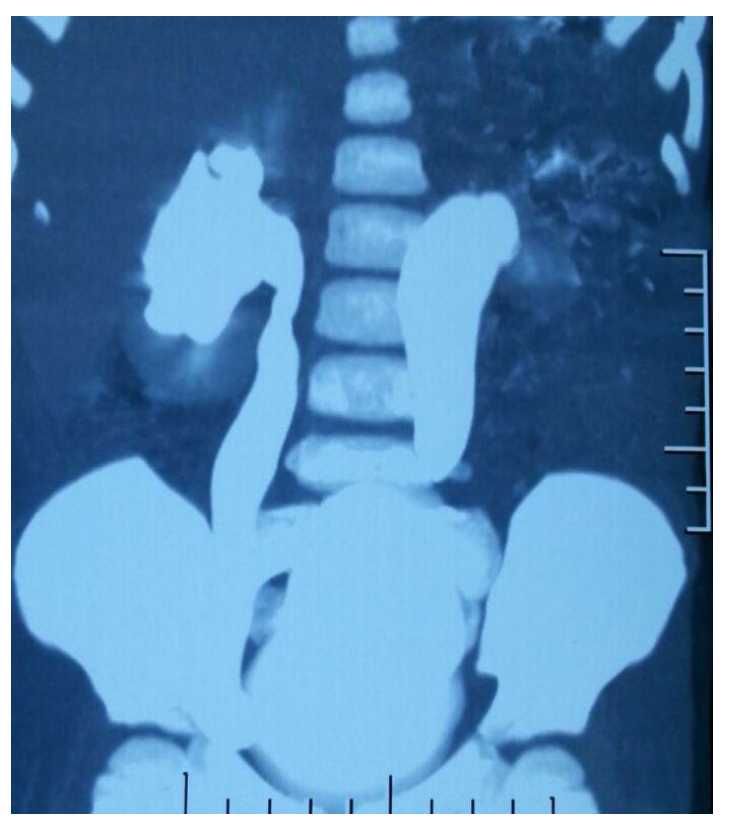

Figure 3b: Contrast in bilateral ureters in CT Urogram on six months follow up. 
Surgical therapy is indicated for the megaureters that are secondary to severe vesicoueretric reflux or obstruction, and it is usually managed with ureteral reimplantation. Occasionally, nephro $\neg$ ureterectomy may be indicated when the func $\neg$ tion of the kidney is severely impaired.

Only a few case reports have been found about segmental megaureter or segmental cystic dilatation of ureter in the literature. In 1995, a case of congenital segmental megaureter with sparing of the proximal and distal ureter, as in our case, has been reported by Ramaswamy et al. [5]. A similar case in a neonate with congenital giant megaureter with duplex kidney presenting as cystic abdominal mass has been reported by Annigery et al. [6]. which was treated with left upper moiety nephroureterectomy? Huang [7] analysed congenital giant megaureter in 21 children, age ranged from 2 months to 8 years. The associated kidney or moiety was hypoplastic, dysplastic, or the site of comparatively mild hydronephrosis associated with atrophic renal parenchyma. Function and volume of the bladder was normal. Twelve of 21 patients had a duplex collecting system on the affected side. Depending on whether the giant segmental ureteral dilatation was multiple or single, these cases have presented either with marked protruberance of the mid and lower abdomen, which was distended by transverse elongated cysts, or with a round cyst mass in the lower abdomen. Nineteen patients treated by excision of the giant megaureter and the associated kidney or moiety were free of symptoms postoperatively. Several theories have been speculated regarding the pathophysiology of segmental megaureter. Ramaswamy suggested that segmental megaureter was a variant of nonrefluxing megaureter and attenuated nexuses and thin myofilaments might be responsible from this entity, as in their case. Although, in another study, it was suggested that ganglionosis might be liable the absence of ganglion cells has not subsequently been confirmed. However, there is no information about innervation patterns in dilated ureteric segment. The treatment of segmental cystic dilatation of ureter should be planned according to the ipsilateral kidney function and length of the normal ureteric segment. If the remaining parts of distal and proximal ureter have enough length, end-to-end ureteroureterostomy after excision of the segmental megaureter should be performed. If excision is not possible, tailoring or trimming of the dilated segment should be considered. If the ipsilateral ureterorenal unit is poorly functioning, hypoplastic or dysplastic, a nephroureterectomy should be planed. Segmental cystic dilatation of ureter must be distinguished from ureterocele and other conditions such as primary megaureter or ureteral diverticulum. At the same time, in the cases of segmental megaureter, the patient should be investigated for possible associated urinary system anomalies such as megacalycosis, duplication of collecting system and hypoplastic, dysplastic or nonfunctioning kidney. Congenital giant megaureter should be considered as one of differential diagnosis in children presenting as abdominal mass.

\section{References}

1. Berrocal T, Lopez-Pereira P, Arjonilla A, Gutiérrez J (2002) Anomalies of the distal ureter, bladder, and urethra in children: embryologic, radiologic, and pathologic features. Radiographics 22: 1139-1164.

2. Scott JE, Renwick M (1988) Antenatal diagnosis of congenital abnormalities in the urinary tract. Results from the Northern Region Fetal Abnormality Survey. Br J Urol 62: 295-300.

3. Mandell GA, Snyder HM 3rd, Heyman S, Keller M, Kaplan JM, et al. (1987) Association of congenital megacalycosis and ipsilateral segmental megaureter. Pediatr Radiol 17: 28-33.

4. Saurabh G, Lahoti BK, Geetika $P(2010)$ Giant megaureter presenting as cystic abdominal mass. Saudi J Kidney Dis Transpl 21: 160-162.

5. Ramaswamy S, Bhatnagar V, Mitra DK, Gupta AK (1995) Congenital segmental giant megaureter. J Pediatr Surg 30: 123-124.

6. Annigeri VM, Hegde HV, Patil PB, Halgeri AB, Rao PR (2012) Congenital giant megaureter with duplex kidney presenting as abdominal lump in a neonate. $\mathrm{J}$ Indian Assoc Pediatr Surg 17: 168-170.

7. Huang CJ (1987) Congenital giant megaureter. J Pediatr Surg 22: 235-239. 